\title{
Association among Depression, Social Anxiety, and Aggression caused by Cyberbullying on Facebook among Sri Lankan Adults
}

\author{
Gunathillake, N.A. ${ }^{1} \&$ Perera, H.K. ${ }^{2}$ \\ nethuviachinthya@gmail.com, perera@gmail.com \\ ${ }^{1}$ Faculty of Health and Life Sciences, Coventry University, Priory Street, Coventry, \\ United Kingdom, CV1 5FB \\ ${ }^{2}$ Asia Pacific Institute of Information Technology, Colombo 02, Sri Lanka
}

\begin{abstract}
Cyberbullying has become a growing social concern as electronic platforms provide perpetrators an alternative medium through which they can easily target their victims from any place, at any time. The present study aimed to investigate whether depression, social anxiety, and aggression were significantly related to cyberbullying perpetration on Facebook among Sri Lankan adults. A cross-sectional, nonexperimental study was conducted using 168 Sri Lankan Facebook users between the ages 21 and 60. Data were collected using an online survey. Cyberbullying perpetration on Facebook, depression, social anxiety, and aggression were assessed using the Prevalence of Facebook Bullying Scale, Center for Epidemiologic Studies Depression Scale (CES-D-10), Interaction Anxiousness Scale, and Brief Aggression Questionnaire respectively. Results of the Spearman correlation analysis revealed that depression and aggression were significantly and positively correlated to cyberbullying perpetration, while there was no significant correlation between social anxiety and cyberbullying perpetration. The findings of the present study provide insight into the importance of addressing the psychological and behavioural issues of perpetrators using appropriate interventions in order to reduce the occurrence of cyberbullying. The study also emphasizes the importance of reporting the incidents of cyberbullying and taking necessary legal actions against the perpetrators.
\end{abstract}

Keywords: Aggression, Cyberbullying, Depression, Facebook, Social Anxiety.

\section{Introduction}

Therapid growth of social media overthecourse of the past decade has substantially changed the nature of everyday social interactions. At present, interacting in cyberspace has become an integral activity embedded in the daily routines of all individuals irrespective of age. Spurred by the popularity of social media, a novel form of communication, online communication, has evolved, replacing the traditional means of communication. Because of this transformation in communication, the phenomenon of cyberbullying has emerged as a growing social concern, replacing traditional bullying. Smith et al. (2008) define cyberbullying as "an aggressive, intentional act carried out by a group or individual using electronic forms of contact, repeatedly and over time against a victim who cannot easily defend him/herself" (p. 376). However, some researchers argue that intentionality, repetition, and power imbalance should not necessarily 
be present in cyberbullying, unlike in face-toface bullying (Slonje et al., 2013). Hence, the above definition remains debatable to date.

\section{Nature of cyberbullying}

Cyberbullying involves three key characteristics which distinguish it from faceto-face bullying. The first characteristic is anonymity, which allows perpetrators a certain degree of freedom from social restrictions and moral responsibilities (Calvete et al., 2010). The second characteristic is publicity or the wider audience. Cyberbullying can be witnessed by an unknown and a large audience on the internet beyond one's social circle. Thus, harmful material can reach large audiences at an incredible speed due to circulation (Meredith, 2010). Therefore, researchers believe that cyberbullying causes a more severe impact than face-to-face bullying (Slonje et al., 2013). The third characteristic is longevity, which refers to the capacity of the internet to store an unlimited amount of content for a long period of time. The longevity of digital content explains why cyberbullying does not necessarily have to be repetitive. Online content such as photos and video clips can be easily replicated and circulated, given the advancement of technology (Boyd \& Ellison, 2007). Hence, the perpetrators do not have any control over the content once it is posted online.

Given the advancement of technologymediated communication, the rate of occurrence of cyberbullying is more frequent in the modern society compared to faceto-face bullying due to its anonymity, less accountability, and easy access given the wide availability of technological devices (Willard,
2007). The technology allows perpetrators to maintain contact with their victims throughout the day, from any place, unlike in face-to-face bullying (Patchin \& Hinduja, 2006). Researchers argue that individuals who are not capable of engaging in face-to-face bullying due to their inferiority in stature or social competency are more likely to involve in cyberbullying (Schenk et al., 2013). According to Patchin and Hinduja (2006), the position of power in cyberbullying could simply stem from an individual's proficiency in utilizing and navigating the modern technology to harass another individual. Thus, unlike traditional bully perpetrators, cyberbully perpetrators could be inferior to the victim.

There is much debate in the literature about the types of cyberbullying. Nevertheless, denigration, flaming, exclusion, harassment, trickery, outing, cyberstalking, and impersonation are the commonly proposed types by researchers in the field (Willard, 2007). Regardless of the type, cyberbullying can be both direct and indirect (Riebel et al., 2009). The prevalence rates of cyberbullying among adolescents range from 20-40\% (Aboujaoude et al., 2015). Generally, it is believed that reports of cyberbullying decrease during the transition from high school to college. However, research evidence reveals that similar rates of cyberbullying are observed among college students, while in some cases these rates can be even higher compared to school students (Gahagan et al., 2016). Moreover, research findings reveal that the rates of prevalence of workplace cyberbullying range from 14-20\% (Snyman \& Loh, 2015). Hence, it is evident that cyberbullying does not reflect a phase in childhood or adolescence, 
but this ill-behaviour can be carried forward into adulthood. Thus, the perpetrators do not naturally grow out of this behaviour as they mature.

\section{The present study}

Cyberbullying is no longer a novel concept, and this phenomenon has been subjected to rigorous scholarly investigation over the past decade. However, majority of the extant literature is on cyberbullying that occurs among adolescents, high school students, and university students (Kokkinos et al., 2016; Schenk et al., 2013). There is a distinct lack of research on cyberbullying that occurs in adulthood. Although cyberbullying that occurs among adults within the specific context of the workplace has been investigated previously (Kowalski et al., 2017; Vranjes et al., 2017), research into general cyberbullying (i.e. context-free) in adulthood is extremely limited.

According to the most recent statistical reports, Facebook is ranked as the number one most popular social network worldwide. It has reached 2797 million monthly active users and 1845 million daily active users by the fourth quarter of 2020 (Facebook Revenue and Usage Statistics, 2021). However, despite the worldwide efforts to investigate the phenomenon of cyberbullying, research on cyberbullying that occurs exclusively through Facebook is extremely limited.

Research on associations between personality characteristics and cyberbullying is abundant (Kokkinos et al., 2016). Also, there is a large body of literature to support that cyberbullying victimization leads to development of psychological issues such as depression and anxiety (Chu et al., 2018; Rosenthal et al., 2016). However, there is limited research on associations between psychological issues such as depression and anxiety, and behavioural issues such as aggression with cyberbullying perpetration. Nevertheless, these limited number of studies also have focused on school students and university students, not adults in general.

A survey conducted by the Sri Lanka Computer Emergency Readiness Team (2020) revealed that $14 \%$ of youth were victimized through cyber-crimes such as identity theft, $11 \%$ reported that their accounts were hacked and $9 \%$ stated that their photos were abused. Despite these worrying incidents, $71 \%$ of respondents admitted to taking no action against the perpetrators. Thus, it is a timely need to investigate the phenomenon of cyberbullying perpetration in the Sri Lankan context. The above justification points out the gap in the extant cyberbullying literature, and hence, provides the rationale for the present study. To bridge this gap, the present study aims to investigate whether depression, social anxiety, and aggression are significantly related to cyberbullying perpetration on Facebook among Sri Lankan adults. Thus, the present study seeks to answer the following questions.

"Are depression, social anxiety, and aggression significantly related to cyberbullying perpetration on Facebook in adulthood?"

According to the Diagnostic and Statistical Manual of Mental Disorders - 5 (DSM-5), depression characterizes "the presence of sad, empty, or irritable mood, accompanied by somatic and cognitive changes that 
significantly affect the individual's capacity to function" (American Psychiatric Association, 2013, p. 155). There is a large body of literature to support that depression is positively associated with cyberbullying (Kowalski et al., 2017; Schenk et al., 2013; \& Selkie et al., 2015). Thus, it was hypothesized that depression would be positively related to cyberbullying perpetration (say, $\mathrm{H}_{1}$ ).

Schlenker \& Leary (1982) define social anxiety as "anxiety resulting from the prospect or presence of personal evaluation in real or imagined social situations" (p. 642). The term social anxiety appears under a variety of labels, but generally it can be classified into two main types as interaction anxiety and audience anxiety (Buss, 1980). Previous studies have found positive associations between social anxiety and cyberbullying perpetration among adolescents (Coelho \& Romão, 2018; Kokkinos et al., 2014). Kokkinos et al. (2014) argue that social anxiety motivates individuals to establish online relationships, due to the discomfort that they experience in real-life social interactions. Furthermore, Kim and Davis (2009) suggest that the feelings of insecurity that one might experience due to social rejection and exclusion may lead to engagement in cyberbullying. Based on the previous literature, the present study hypothesized that social anxiety would be positively related to cyberbullying perpetration (say, $\mathrm{H}_{2}$ ).

Aggression is "any behaviour intended to harm another person who does not want to be harmed" (Baumesiter \& Bushman, 2008, p. 290). Cyberbullying itself is an aggressive behaviour (Smith et al. 2008). Ybarra and Mitchell (2004) claim that perpetrators of cyberbullying tend to have aggression issues.
According to Olweus (1994), reasons like the desire for power and domination, and rivalry explain why aggression underlies bullying perpetration. According to Salmivalli \& Nieminen (2002) cyberbully perpetrators can be either proactive aggressors or reactive aggressors. Past studies have found significant positive associations between aggression and cyberbullying perpetration (Savage \& Tokunaga, 2017; Schenk et al., 2013; Schultze-Krumbholz \& Scheithauer, 2012). Thus, it was hypothesized that aggression would be positively related to cyberbullying perpetration (say, $\mathrm{H}_{3}$ ).

\section{Materials and Methods \\ Participants and procedure}

The study adopted a cross-sectional, nonexperimental, and a quantitative research design. The study sample consisted of 168 Sri Lankan adults between the ages 21-60 ( $\mathrm{n}=168$ ), who were proficient in English and active Facebook users. Participants were recruited through convenience sampling. 88\% of the respondents belonged to the age group 21-30 and $60 \%$ were females. The highest level of education received by the majority $(40 \%)$ was an undergraduate degree, and the majority (45\%) were full-time students. Data were collected using an online survey using a structured questionnaire. The web link for the survey questionnaire was shared via Facebook and Messenger. The study was conducted in accordance with the ethical guidelines of the British Psychological Society. The informed consent of the participants was obtained prior to the study. The participation in this study was entirely voluntary, and the anonymity and the confidentiality of the participants were assured throughout the study. 


\section{Measures}

A demographic questionnaire was used to gather the age, gender, the highest level of education, and the current employment status of the respondents. Self-report scales were used to assess the variables, cyberbullying perpetration on Facebook, depression, social anxiety and aggression.

\section{Prevalence of Facebook bullying scale}

Cyberbullying perpetration on Facebook was assessed using the 18-item Prevalence of Facebook Bullying Scale (Kwan \& Skoric, 2013; Cronbach's $\alpha=.86$ ). Respondents had to indicate the number of times that they have engaged in specific cyberbullying behaviour during the past month, on a scale ranging from 0 to 5 , where $0=$ "Never", 1 = "Once", 2 = "2-4 times", 3 = "5-7 times", 4 = "8-10 times" and $5=$ "More than 10 times". It consisted of items such as "I have sent nasty messages to someone on Facebook to upset the person" and "I have spread rumours about someone on Facebook to damage the person's reputation". The scores ranged from 0-90. The score for the variable was created by summing the scores on all scale items. A score equal to or above 45 indicated higher levels of cyberbullying.

\section{Center for Epidemiologic studies depression scale (CES-D-10)}

Respondents' prevalence of depressive symptoms during the past week was assessed using the 10-item CES-D-10 (Andresen et al., 1994; Cronbach's $\alpha=.86$ ). This scale is a revised and short version of the original 20-item Center for Epidemiologic Studies
Depression Scale (Radloff, 1977) and used for general population. Responses were given on a 4-point Likert-scale ranging from 0 to 3, where $0=$ "Rarely or none of the time" (less than 1 day), 1 = "Some or a little of the time" (1-2 days), 2 = "Occasionally or a moderate amount of time" (3-4 days) and $3=$ "Most or all of the time" (5-7 days). Sample items include "I was bothered by things that usually don't bother me" and "I had trouble keeping my mind on what I was doing". The scores ranged from 0 to 30 . According to the scoring of the CES-D-10, any score equal to, or above 10 is considered as depressed. The score for the variable was created by summing the scores on all scale items.

\section{Interaction anxiousness scale (IAS)}

Social anxiety was assessed using the 15item IAS (Leary, 1983; Cronbach's $\alpha=.89$ ). It consisted of items such as "I often feel nervous even in casual get-togethers" and "I am usually at ease when speaking to a member of the opposite sex". Responses were given on a 5-point Likert-scale, where $1=$ "Not at all characteristic of me", 2 = "Slightly characteristic of me", $3=$ "Moderately characteristic of me", 4 = "Very characteristic of me" and $5=$ "Extremely characteristic of me". The scores ranged from 15 to 75 . The score for the variable was created by summing the scores on all scale items. A score $\geq 45$ was considered as higher levels of social anxiety.

\section{Data analysis}

The statistical analysis of data was performed using IBM SPSS Statistics 20 software. Preliminary analyses were conducted initially to screen for missing data, outliers, and normality. Missing data were replaced with 
the mean score for that scale item across the sample. Multivariate outliers were detected using the Mahalanobis distance statistic with 93.17 being the cut-off score. After one round of screening, 17 multivariate outliers were detected. However, a final decision was made to retain theses outliers as they provided an accurate representation of data. Descriptive statistics and the correlation matrix among the four variables were obtained.

\section{Results and Discussion}

Results

As indicated in Table 1, the engagement in cyberbullying perpetration in the study sample was extremely low (4.61). Only $0.6 \%$ indicated higher levels of cyberbullying. Majority of the respondents were not depressed as the mean score (7.69) was below 10. Only $28 \%$ scored high for depression. Majority of the respondents scored less for social anxiety and the corresponding mean was 39.18. Only $23 \%$ indicated higher levels of social anxiety. Majority of the sample scored low for aggression and the corresponding mean was 34.10.

Table 1.

Descriptive statistics of the variables

\begin{tabular}{lcccc}
\hline Variable & Mean & SD & Min & Max \\
\hline Cyberbullying & 4.61 & 6.27 & 0 & 59 \\
\hline Depression & 7.69 & 4.81 & 0 & 27 \\
\hline Social Anxiety & 39.18 & 8.69 & 19 & 65 \\
\hline Aggression & 34.10 & 7.87 & 12 & 57 \\
\hline $\begin{array}{l}\text { The mean score for } \\
\text { significantly higher }(p<.05) \text { in males }(6.54)\end{array}$
\end{tabular}

than in females (3.34). No significant difference was found for mean depression as well mean aggression between gender. However, mean social anxiety for females was significantly higher than that for males $(t=-2.47, p<.05)$.

The Cronbach's $\alpha$ for cyberbullying (0.83), depression (0.74), social anxiety $(0.81)$, and aggression (0.76) are higher than the minimum recommended value of 0.70 . The correlation matrix among the four variables is shown in the Table 2 .

\section{Table 2.}

The correlation coefficients among the four variables

\begin{tabular}{lccc}
\hline & Cyberbullying & Depression & $\begin{array}{c}\text { Social } \\
\text { anxiety }\end{array}$ \\
\hline Depression & $0.30^{*}$ & & \\
$\begin{array}{l}\text { Social } \\
\text { anxiety }\end{array}$ & 0.06 & $0.24^{*}$ & \\
Aggression & $0.29^{*}$ & $0.30^{*}$ & 0.14 \\
\hline
\end{tabular}

* Significant at least 5\% level

As shown in the Table 2, there is a significant positive correlation between depression and cyberbullying perpetration $(r=.30, p<.05)$, as well as aggression and cyberbullying perpetration $(r=.29, p<.05)$. There is no significant correlation between social anxiety and cyberbullying perpetration.

\section{Discussion}

The primary aim of the present study was to investigate whether depression, social anxiety, and aggression were significantly related to cyberbullying perpetration on 
Facebook among Sri Lankan adults. However, in contrary to the researchers' expectations, the engagement in cyberbullying perpetration in the study sample was extremely low. A possible reason for this could be the effect of demographic variables, which could have acted as confounding variables in the study.

H1 predicted that depression would be positivelyrelated tocyberbullyingperpetration. As expected, the findings revealed that there was a significant positive correlation between depression and cyberbullying perpetration, supporting H1. This finding is consistent with the past research findings (Kowalski et al., 2017; Schenk et al., 2013; Selkie et al., 2015). However, the mean score for depression in the sample was below the cut off score.

H2 predicted that social anxiety would be positively related to cyberbullying perpetration. The results indicated a weak positive correlation between social anxiety and cyberbullying perpetration; however, this correlation was not significant. Therefore, in contrary to the researchers' expectations, H2 was not supported. This finding is contradictory to the research findings of Kokkinos et al. (2014) and Coelho \& Romão (2018), where the samples were adolescents. A possible logical explanation for these contradictory findings may be that unlike in adolescence, in adulthood there are other significant predictors of cyberbullying perpetration than social anxiety. For an example, the need to belong and the fear of social rejection are intense during adolescence, and as individuals mature, they are less concerned about such needs. Thus, engaging in online harassment as a means of overcoming feelings of insecurity may not be common during adulthood. However, further research is required to confirm this, as this is only a logical explanation in the researchers' point of view, and not a theoretical explanation.

H3 predicted that aggression would be positively related to cyberbullying perpetration. As predicted, there was a significant positive correlation between aggression and cyberbullying. Therefore, H3 was supported. This result is coherent with the research findings of Savage and Tokunaga (2017), Schenk et al. (2013), and SchultzeKrumbholz \& Scheithauer (2012).

A major strength of the present study is that reliability coefficients of all the scales used in the study were greater than .70. The most notable limitation of this study is collecting data exclusively online, as the researcher had no control over who could respond to the survey. Also, the findings lack population validity as the study sample was not representative of the general adult population as data were collected through convenience sampling using a small sample size, and the survey was conducted only in English. Finally, the multivariate outliers would have had a significant effect on the findings of the study.

\section{Conclusions, Recommendations, and Suggestions}

Findings of the present study reveal that depression and aggression are significantly related to cyberbullying perpetration in adulthood. In the light of these findings, it is crucial to address these underlying psychological and behavioural issues of cyberbullying perpetrators with appropriate assessment and treatment to minimize the occurrence of this behaviour in future. 
Educators should take necessary steps to educate the Facebook users to effectively use this social networking site, instead of using it as a tool of harassment. On the other hand, Facebook users should be educated to be more cautious when sharing public material or accepting friend requests from strangers, to reduce the chance of being a cyberbully victim. Most importantly, it should be brought to attention that, online harassment is against the law, and hence, both the victims and witnesses of cyberbullying should be encouraged to report such incidents.

Interestingly, research suggests that individuals are more likely to report another person being victimized in cyberspace, than they are to report their own victimization experience. Hence, it is recommended that creating a website where both the victims and witnesses can report the incidents of cyberbullying anonymously will encourage people to report cases of cyberbullying.

To date, Sri Lanka does not have a national policy framework to ensure cyber security. Therefore, law enforcement and policy makers should play a more active role in enacting cybercrime legislation and revising the existing Computer Crime Act. Although there are authorities responsible for online safety such as Sri Lanka Computer Emergency Readiness Team (SL-CERT), they still need to improve their ability to control online harassment. On the other hand, although authorities (e.g. National Child Protection Authority - NCPA), show an active interest in ensuring the online safety of children in Sri Lanka, less attention has been devoted to ensuring the online safety of adults, which is a timely need.
The present study provides the framework for future research inquiry on cyberbullying. As with any empirical research, replication is essential to gain a deeper understanding of the phenomenon of cyberbullying. Future research should address the limitations of the present study. Furthermore, it would be interesting to investigate whether cyberbully perpetrators were once traditional bullies who have migrated to an electronic platform to accomplish their intentions, or whether they have no history of traditional bullying. On the other hand, it would be interesting to find out whether these adults were bullies during their adolescence as well. Finally, it might be useful to take into consideration factors which might prevent an individual from engaging in cyberbullying such as the subjective evaluation of the potential risks of engaging in cyberbullying, and the ability to exercise self-control over the behavioral intention and social norms.

\section{References}

Aboujaoude, E., Savage, M. W., Starcevic, V., \& Salame, W. O. (2015). Cyberbullying: Review of an old problem gone viral. Journal of Adolescent Health, 57(1), 10-18. https://doi.org/10.1016/j. jadohealth.2015.04.011.

American Psychiatric Association. (2013). Diagnostic and Statistical Manual of Mental Disorders, 5th Edition: DSM5 (5th ed.). American Psychiatric Publishing.

Andresen, E. M., Malmgren, J. A., Carter, W. B., \& Patrick, D. L. (1994). Screening for depression in well older adults: Evaluation of a short form of the CES-D. American Journal of Preventive Medicine, 10(2), 77-84. https://doi. org/10.1016/s0749-3797(18)30622-6. 
Baumeister, R. F., \& Bushman, B. J. (2008). Social Psychology and Human Nature (2nd ed.). Cengage Learning.

Boyd, D. M., \& Ellison, N. B. (2007). Social network sites: Definition, history, and scholarship. Journal of ComputerMediated Communication, 13(1), 210230. https://doi.org/10.1111/j.10836101.2007.00393.x.

Buss, A. H. (1980). Self-consciousness and social anxiety. W. H. Freeman.

Buss, A.H., \& Perry, M. (1992). The aggression questionnaire. Journal of Personality and Social Psychology, 63(3), 452459. https://doi.org/10.1037/00223514.63.3.452.

Calvete, E., Orue, I., Estévez, A., Villardón, L., \& Padilla, P. (2010). Cyberbullying in adolescents: Modalities and aggressors' profile. Computers in Human Behavior, 26(5), 1128-1135. https://doi. org/10.1016/j.chb.2010.03.017.

Cassidy, W., Jackson, M., \& Brown, K. N. (2009). Sticks and stones can break my bones, but how can pixels hurt me? School Psychology International, 30(4), 383-402. $\quad$ https://doi. org/10.1177/0143034309106948.

Chu, X. W., Fan, C. Y., Liu, Q. Q., \& Zhou, Z. K. (2018). Cyberbullying victimization and symptoms of depression and anxiety among Chinese adolescents: Examining hopelessness as a mediator and self-compassion as a moderator. Computers in Human Behavior, 86, 377-386. https://doi.org/10.1016/j. chb.2018.04.039.

Coelho, V. A., \& Romão, A. M. (2018). The relation between social anxiety, social withdrawal and (cyber) bullying roles: A multilevel analysis. Computers in Human Behavior, 86, 218-226. https:// doi.org/10.1016/j.chb.2018.04.048.

Facebook Revenue and Usage Statistics (2021). (2021, April 6). Business of Apps. https://www.businessofapps. com/data/facebook-statistics/.

Gahagan, K., Vaterlaus, J. M., \& Frost, L. R. (2016). College student cyberbullying on social networking sites: Conceptualization, prevalence, and perceived bystander responsibility. Computers in Human Behavior, 55, 1097-1105. https://doi.org/10.1016/j. chb.2015.11.019.

Kim, H. K., \& Davis, K. E. (2009). Toward a comprehensive theory of problematic Internet use: Evaluating the role of self-esteem, anxiety, flow, and the selfrated importance of Internet activities. Computers in Human Behavior, 25(2), 490-500. https://doi.org/10.1016/j. chb.2008.11.001.

Kokkinos, C. M., Antoniadou, N., \& Markos, A. (2014). Cyber-bullying: An investigation of the psychological profile of university student participants. Journal of Applied Developmental Psychology, 35(3), 204-214. https:// doi.org/10.1016/j.appdev.2014.04.001.

Kokkinos, C. M., Baltzidis, E., \& Xynogala, D. (2016). Prevalence and personality correlates of Facebook bullying among university undergraduates. Computers in Human Behavior, 55, 840-850. https://doi.org/10.1016/j. chb.2015.10.017.

Kowalski, R. M., Toth, A., \& Morgan, M. (2017). Bullying and cyberbullying 
in adulthood and the workplace. The Journal of Social Psychology, 158(1), 64-81. https://doi.org/10.1080/002245 45.2017.1302402.

Kwan, G. C. E., \& Skoric, M. M. (2013). Facebook bullying: An extension of battles in school. Computers in Human Behavior, 29(1), 16-25. https://doi. org/10.1016/j.chb.2012.07.014

Leary, M. R. (1983). Social anxiousness: The construct and its measurement. Journal of Personality Assessment, 47(1), 66-75. https://doi.org/10.1207/ s15327752jpa4701_8.

Meredith, J. P. (2010). Combating cyberbullying: Emphasising education over criminalisation. Federal Communications Law Journal, 63 (1), 311-340.

Olweus, D. (1994). Bullying at school: Basic facts and effects of a school based intervention program. Journal of Child Psychology and Psychiatry, 35(7), 1171-1190. https://doi. org/10.1111/j.1469-7610.1994. tb01229.x.

Patchin, J. W., \& Hinduja, S. (2006). Bullies move beyond the schoolyard. Youth Violence and Juvenile Justice, 4(2), 148-169. https://doi. org/10.1177/1541204006286288.

Radloff, L. S. (1977). The CES-D Scale. Applied Psychological Measurement, 1(3), 385-401. https://doi. org/10.1177/014662167700100306.

Riebel, J. Jager, R. S., \& Fischer, U. C. (2009). Cyberbullying in Germany: An exploration of prevalence, overlapping with real life bullying and coping strategies. Psychology Science

Quarterly, 51, 298-314.

Salmivalli, C., \& Nieminen, E. (2002). Proactive and reactive aggression among school bullies, victims, and bully-victims. Aggressive Behavior, 28(1), 30-44. https://doi.org/10.1002/ ab. 90004 .

Savage, M. W., \& Tokunaga, R. S. (2017). Moving toward a theory: Testing an integrated model of cyberbullying perpetration, aggression, social skills, and Internet self-efficacy. Computers in Human Behavior, 71, 353-361. https:// doi.org/10.1016/j.chb.2017.02.016.

Schenk, A. M., \& Fremouw, W. J. (2012). Prevalence, psychological impact, and coping of cyberbully victims among college students. Journal of School Violence, 11(1), 21-37. https://doi.org/ 10.1080/15388220.2011.630310.

Schenk, A. M., Fremouw, W. J., \& Keelan, C. M. (2013). Characteristics of college cyberbullies. Computers in Human Behavior, 29(6), 2320-2327. https:// doi.org/10.1016/j.chb.2013.05.013.

Schlenker, B. R., \& Leary, M. R. (1982). Social anxiety and self-presentation: A conceptualization model.Psychological Bulletin, 92(3), 641-669. https://doi. org/10.1037/0033-2909.92.3.641.

Schultze-Krumbholz, A., Jäkel, A., Schultze, M., \& Scheithauer, H. (2012). Emotional and behavioural problems in the context of cyberbullying: a longitudinal study among German adolescents. Emotional and Behavioural Difficulties, 17(3-4), 329-345. https://doi.org/10.1080/1363 2752.2012.704317. 
Schultze-Krumbholz, A., \& Scheithauer, H. (2009). Social-behavioral correlates of cyberbullying in a German student sample. Zeitschrift Für Psychologie / Journal of Psychology, 217(4), 224226. https://doi.org/10.1027/00443409.217.4.224.

Selkie, E. M., Kota, R., Chan, Y. F., \& Moreno, M. (2015). Cyberbullying, depression, and problem alcohol use in female college students: A multisite study. Cyberpsychology, Behavior, and Social Networking, 18(2), 79-86. https://doi. org/10.1089/cyber.2014.0371.

Slonje, R., Smith, P. K., \& Frisén, A. (2013). The nature of cyberbullying, and strategies for prevention. Computers in Human Behavior, 29(1), 26-32. https:// doi.org/10.1016/j.chb.2012.05.024.

Smith, P. K., Mahdavi, J., Carvalho, M., Fisher, S., Russell, S., \& Tippett, N. (2008). Cyberbullying: its nature and impact in secondary school pupils. Journal of Child Psychology and Psychiatry, 49(4),376-385.https://doi.org/10.1111/ j.1469-7610.2007.01846.x.

Sri Lanka Computer Emergency Readiness Team. (2020). Sri Lanka Computer Emergency Readiness Team. https:// www.cert.gov.lk/.

Strahan, R., \& Gerbasi, K. C. (1972). Short, homogeneous versions of the MarlowCrowne Social Desirability Scale. Journal of Clinical Psychology, 28(2), 191-193.

Vranjes, I., Baillien, E., Vandebosch, H., Erreygers, S., \& De Witte, H. (2017). The dark side of working online: Towards a definition and an Emotion Reaction model of workplace cyberbullying. Computers in Human Behavior, 69, 324-334. https://doi. org/10.1016/j.chb.2016.12.055.

Webster, G. D., DeWall, C. N., Pond, R. S., Deckman, T., Jonason, P. K., Le, B. M., Nichols, A. L., Schember, T. O., Crysel, L. C., Crosier, B. S., Smith, C. V., Paddock, E. L., Nezlek, J. B., Kirkpatrick, L. A., Bryan, A. D., \& Bator, R. J. (2013). The brief aggression questionnaire: psychometric and behavioral evidence for an efficient measure of trait aggression. Aggressive Behavior, 40(2), 120-139. https://doi. org/10.1002/ab.21507.

Willard, N. E., \& Steiner, K. (2007). Cyberbullying and Cyberthreats: Responding to the Challenge of Online Social Aggression, Threats, and Distress (2nd ed.). Research Press.

Ybarra, M. L., \& Mitchell, K. J. (2004). Youth engaging in online harassment: associations with caregiver-child relationships, Internet use, and personal characteristics. Journal of Adolescence, 27(3), 319$336 . \quad$ https://doi.org/10.1016/j. adolescence.2004.03.007. 